\title{
New drugs, new challenges for dermatologists: mucocutaneous ulcers secondary to everolimus*
}

\author{
Victor Pavan Pasin ${ }^{1}$ \\ Kalline Andrade de Carvalho ${ }^{1}$ \\ Milvia Maria Simões e Silva Enokihara ${ }^{1}$
}

\author{
Amanda Regio Pereira ${ }^{1}$ \\ João Marcos Góes de Paiva ${ }^{1}$ \\ Adriana Maria Porro ${ }^{1}$
}

DOI: http:/ /dx.doi.org/10.1590/abd1806-4841.20153672

\begin{abstract}
A bstract: Everolimus, a mammalian target of rapamycin inhibitor, is an emerging drug, which is being increasingly applied in oncology and solid organ transplantation. Oral ulcers are a frequent side effect associated with this immunosupressor. We report the case of a renal transplant recipient who developed disfiguring oral and perianal ulcers secondary to everolimus's toxicity. This is probably the first report of perianal involvement. Dermatologists need to be aware of the potential mucocutaneous adverse effects related to these new drugs that are becoming evermore common in our clinical practice.
\end{abstract}

Keywords: Drug eruptions; Immunosuppressive agents; Ulcer

\section{INTRODUCTION}

Mammalian target of rapamycin (mTOR) inhibitors, such as sirolimus and everolimus, are emerging drugs, which are being increasingly applied in oncology and to help prevention of rejection in solid organ transplant recipients ${ }^{1}$ Oral ulcers have been reported as one of the most common side effects of everolimus, affecting up to $70 \%$ of the patients treated with this drug, leading to discontinuation of the therapy in many cases. ${ }^{2,3}$ We report a case of oral and perianal ulcers secondary to everolimus in a renal transplant recipient, highlighting the severity of the lesions and the perianal involvement, which has not yet been described in indexed medical journals.

\section{CASE REPORT}

A 38-year-old, female patient with end-stage renal disease of unknown etiology, submitted to renal transplantation 3 months earlier, was hospitalized due to oral and perianal ulcers she had suffered from over the preceding 14 days, which were resistant to empirical therapy with oral acyclovir for 10 days $(400 \mathrm{mg} \mathrm{ev-}$ ery 8 hours). She had been under immunosuppression with mycophenolate sodium (720mg daily), prednisone (30 mg daily) and everolimus (0.5 $\mathrm{mg}$ daily). The latter had been introduced 2 months earlier. The patient was also diagnosed HIV positive 3 years before and presented with undetectable viral load and a CD4 count of 308 cells $/ \mu \mathrm{L}$ upon admission, attributable to effective antiretroviral therapy (ART) with zidovudine, lamivudine, atazanavir and ritonavir. Dermatology consultation was requested by the nephrology team. On examination, two oral ulcers were found on the superior lip and tongue. Both were deep and painful, and the labial lesion was partially necrotic and quite disfiguring (Figure 1). A deep, $2 \mathrm{~cm}$-diameter ulcer in the perianal region was also observed (Figure 2). Histopathology of both sites revealed chronic, non-specific ulcers, with scarce inflammatory lymphocytic infiltrate (Figure 3). Signs of viral infection were absent on histology. Immunohistochemical detection of herpes simplex virus 1 and 2 and cytomegalovirus (CMV) resulted negative in these tissue samples. Antigenemia assay and blood polymerase chain reaction for CMV were also negative. Everolimus blood level was $11.7 \mathrm{ng} / \mathrm{ml}$, which is above the target (3-8

\footnotetext{
Received on 04.05.2014

Approved by the Advisory Board and accepted for publication on 21.05.2014

Work performed at the Universidade Federal de São Paulo (UNIFESP) - São Paulo, Brazil.

Financial Support: None.

Conflict of Interest: None.

1 Universidade Federal de São Paulo (UNIFESP) - São Paulo, Brazil.

(C2015 by Anais Brasileiros de Dermatologia
} 
$\mathrm{ng} / \mathrm{ml}$ ), also favoring the possibility of drug-related toxicity, a diagnosis of exclusion in this case. The ulcers started to heal after everolimus discontinuation. Complete reepithelization, though, was observed only after 40 days. A residual deformity with aesthetic and functional impairment remained in the superior lip, affecting movements such as suction (Figure 4).

\section{DISAUSSION}

mTOR inhibitor-associated stomatitis is a newly recognized and frequent drug-related complication. It is a significant toxicity that leads to dose modifications, treatment delay and interruption of antineoplastic and immunosuppressive regimens. ${ }^{2,45}$ Lesions are usually described as painful, long-lasting oval ulcerations that resemble aphthous or herpetic stomatitis. ${ }^{3,46}$ Although its mechanisms remain unknown, it seems that the frequency, duration and severity of this
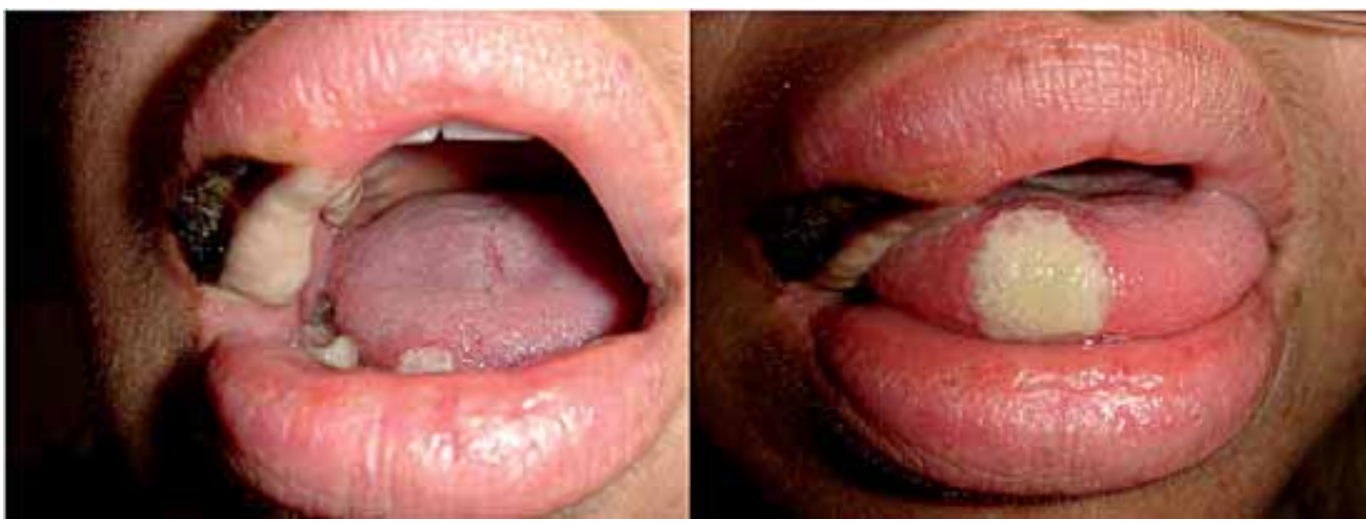

\section{Figure 1:}

Deep and painful oral ulcers, partially necrotic and quite disfiguring

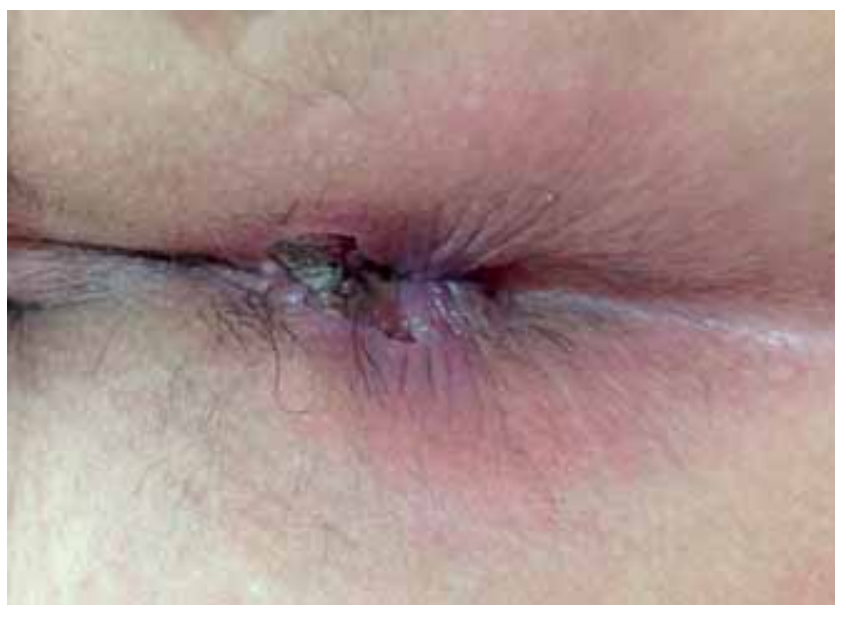

FIgURE 2: Deep, perianal ulcer, involving the skin and semi-mucous surface side effect are associated with high doses and blood levels of everolimus. . $, 3,6,7$ Empiric treatments, such as sodium bicarbonate-based mouthwash and oral fluconazole, appear to be useless and managing the condition remains challenging. ${ }^{3}$

Some aspects in the case reported are unusual, namely the severity of ulcers that led to tissue loss and drug discontinuation, and the perianal involvement, a location that has not yet been mentioned in the indexed literature, according to extensive research in the major online databases.

Everolimus metabolism occurs predominantly by means of the hepatic cytochrome P450 system, resulting in multiple, possible pharmacological interactions. $^{8}$
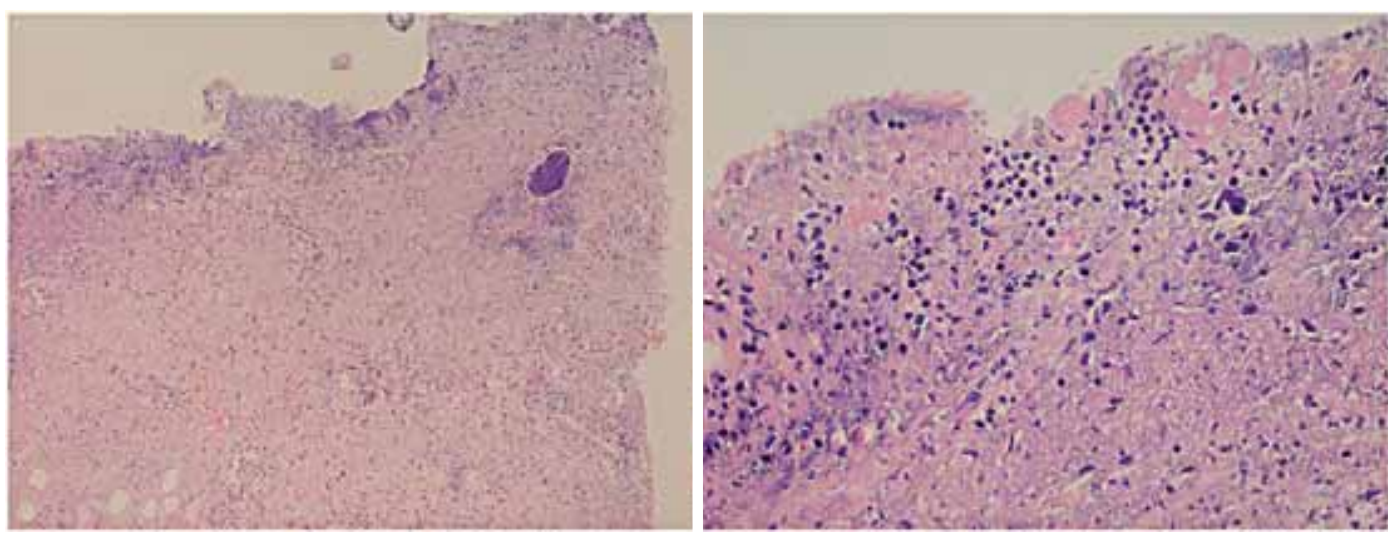

\section{Figure 3:}

Histopathological aspects: chronic non-specific ulcer, with scarce inflammatory lymphocytic infiltrate. Hematoxylin and eosin stain, 100x and 400x 


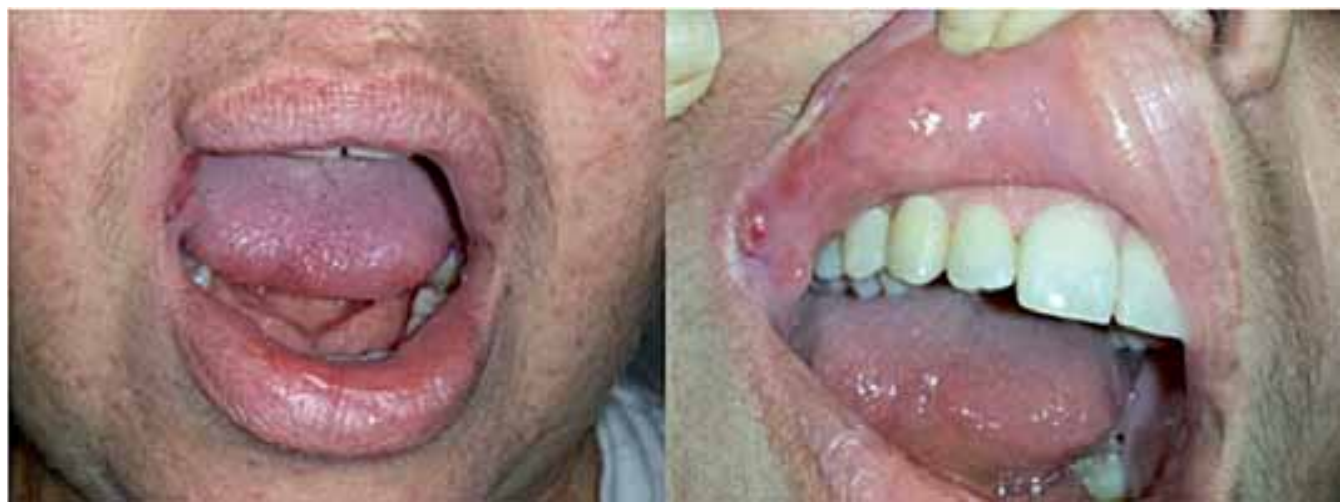

Figure 4:

Complete reepithelization 40 days after everolimus discontinuation. Residual deformity in the superior lip, with aesthetic and functional impairment
Blood levels above target that were detected in this patient could be attributed to drug interaction, probably with the protease inhibitors, atazanavir and ritonavir, which are potent inhibitors of the cytochrome P450 enzymes. ${ }^{9,10}$

\section{REFERENCES}

1. Peterson ME. Management of adverse events in patients with hormone receptorpositive breast cancer treated with everolimus: observations from a phase III clinical trial. Support Care Cancer. 2013;21:2341-9.

2. Martins F, de Oliveira MA, Wang Q, Sonis S, Gallottini M, George S, et al. A review of oral toxicity associated with mTOR inhibitor therapy in cancer patients. Oral Oncol. 2013;49:293-8.

3. Ferté C, Paci A, Zizi M, Gonzales DB, Goubar A, Gomez-Roca C, et al. Natural history, management and pharmacokinetics of Everolimus induced-oral ulcers: Insights into compliance issues. Eur J Cancer. 2011;47:2249-55

4. Boers-Doets CB, Epstein JB, Raber-Durlacher JE, Ouwerkerk J, Logan RM, Brakenhoff JA, et al. Oral Adverse Events Associated with Tyrosine Kinase and Mammalian Target of Rapamycin Inhibitors in Renal Cell Carcinoma: A Structured Literature Review. Oncologist. 2012;17:135-44.

5. Lee WJ, Lee JL, Chang SE, Lee MW, Kang YK, Choi JH, et al. Cutaneous adverse effects in patients treated with the multitargeted kinase inhibitors sorafenib and sunitinib. Br J Dermatol. 2009;161:1045-51.

6. Soefje SA, Karnad A, Brenner AJ. Common toxicities of mammalian target of rapamycin inhibitors. Target Oncol. 2011;6:125-9.

7. Campistol JM, de Fijter JW, Flechner SM, Langone A, Morelon E, Stockfleth E. mTOR inhibitor-associated dermatologic and mucosal problems. Clin Transplant. 2010;24:149-56

8. Gurk-Turner C, Manitpisitkul W, Cooper M. A Comprehensive Review of Everolimus Clinical Reports: A New Mammalian Target of Rapamycin Inhibitor. Transplantation. 2012;94:659-68.

9. Busti AJ, Hall RG, Margolis DM. Atazanavir for the treatment of human immunodeficiency virus infection. Pharmacotherapy. 2004;24:1732-47. Josephson F. Drug-drug interactions in the treatment of HIV infection: focus on pharmacokinetic enhancement through CYP3A inhibition. J Intern Med. 2010;268:530-9.
In conclusion, we stress the need for dermatologists to become familiar with these new drugs and related mucocutaneous adverse effects, which are becoming increasingly frequent in our practice. A multidisciplinary approach is essential for the appropriate management of cases like the one reported.]

H ow to cite this article: Pasin VP, Pereira AR, Carvalho KA, Paiva JMG, Enokihara MMSS, Porro AM. New drugs, new challenges to dermatologists: mucocutaneous ulcers secondary to everolimus. An Bras Dermatol. 2015;90 (3 Suppl 1):S165-7. 